\title{
VIDEOCARE: Decentralised psychiatric emergency care through videoconferencing
}

\author{
Marianne V Trondsen ${ }^{1 *}$, Stein Roald Bolle ${ }^{1,2}$, Geir Øyvind Stensland ${ }^{3}$ and Aksel Tjora ${ }^{1,4}$
}

\begin{abstract}
Background: Today the availability of specialists is limited for psychiatric patients in rural areas, especially during psychiatric emergencies. To overcome this challenge, the University Hospital of North Norway has implemented a new decentralised on-call system in psychiatric emergencies, by which psychiatrists are accessible by videoconference 24/7. In September 2011, the new on-call system was established in clinical practice for patients and health staff at three regional psychiatric centres in Northern Norway. Although a wide variety of therapies have been successfully delivered by videoconference, there is limited research on the use of videoconferenced consultations with patients in psychiatric emergencies. The aim of this study is to explore the use of videoconference in psychiatric emergencies based on the implementation of this first Norwegian tele-psychiatric service in emergency care.

Methods/design: The research project is an exploratory case study of a new videoconference service in operation. By applying in-depth interviews with patients, specialists and local health-care staff, we will identify factors that facilitate and hinder use of videoconferencing in psychiatric emergencies, and explore how videoconferenced consultations matter for patients, professional practice and cooperation between levels in psychiatric care. By using an on-going project as the site of research, the case is especially well-suited for generating reliable and valid empirical data.
\end{abstract}

Discussion: Results from the study will be of importance for understanding of how videoconferencing may support proper treatment and high-quality health care services in rural areas for patients in psychiatric emergencies.

Keywords: Psychiatry, Emergency care, Videoconference, Telemedicine, Tele-psychiatry, Norway, Qualitative study

\section{Background}

Mental illness has become a significant health challenge worldwide $[1,2]$. The need to improve mental health services to enhance treatment access and quality is therefore urgent $[2,3]$. Currently, shorter hospital stays and provision of mental health care on the municipal level $[2,4]$ are supposed to meet increased demands of health services in the future, supported by better integration between levels of health care providers through the use of ICT [5-7]. Based on the aim of "Proper treatment - at the right place and right time", a key step in the new Norwegian Coordination Reform is to ensure that the specialist health care services are able to apply

\footnotetext{
* Correspondence: marianne.trondsen@telemed.no

${ }^{1}$ Norwegian Centre for Integrated Care and Telemedicine (NST), University Hospital of North Norway (UNN), P.O. Box 35, Tromsø N-9038, Norway Full list of author information is available at the end of the article
}

specialised competence to a greater extent, and contribute to development of expertise in municipal health care [7].

Recruiting and maintaining a sufficient number of clinical experts outside larger cities are a challenge [8-10], and tele-psychiatry, by real-time videoconferences (VC), is supposed to provide advanced consultative services and educational initiatives to areas with lack of psychiatrists [11]. A wide variety of therapies have been successfully delivered by tele-psychiatry, addressing a broad range of diagnoses and mental health issues $[3,8,9,11-14]$. These applications have increased the patients' access to therapy, increased patients' satisfaction, saved time and reduced patients' travel needs $[3,8,9,14,15]$. Exploring young people's experiences with tele-psychiatric consultations, Boydell et al. (2010) found that videoconferencing alleviated the patients' anxieties regarding the encounter with a psychiatrist [8]. Moreover, Greenberg

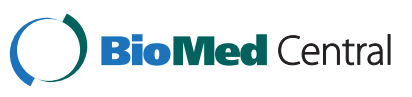


et al. (2006) reported that access to psychiatric expertise reduced burden on family caregivers, whilst local service providers experienced feelings of enhanced capacity by the increased knowledge, confidence and sense of competence in assisting their clients [11].

There is, however, limited research on videoconferencing used for emergency consultations in psychiatry $[16,17]$. Although experience is limited, it has been stated that acute tele-psychiatry has the potential to improve patient care and reduce emergency department overcrowding [16]. It is found to be safe, reliable for treatment and diagnoses, as well as satisfactory to emergency health staff and patients treated [16,18]. In somatic emergency medicine, videoconferencing has been successfully applied for team interactions between hospitals, and for complex and time-critical medical assessment and treatment [19-21].

While much of the evidence speaks in favour of telepsychiatry, current social research of implementation of telemedicine and e-health services suggests that experiences and expectations of interaction between users and providers of such services are complex and challenging [22-28] and need further consideration. For instance, patient satisfaction studies for telemedical applications must be regarded as only partial evidence of service quality because of patients' often uncritical trust in services [29]. Approaches need to include patients' and health-care professionals' experiences, as well as clinical, social, cultural and organisational aspects of implementation of telemedicine.

In this study we explore the use of video-conferenced consultations in psychiatric emergencies, based on the implementation of the first Norwegian tele-psychiatry service in emergency care established by the University Hospital of North Norway (UNN).

\section{Methods/Design}

\section{Site of research}

Department South in the General Psychiatric Clinic at UNN consists of a hospital section and three regional psychiatric centres. Because of the geographical remoteness of the regional psychiatric centres, they have not succeeded in recruiting enough psychiatrists for a $24 / 7$ robust on-call service. To overcome this challenge, Department South has, in collaboration with the Norwegian Centre for Integrated Care and Telemedicine (NST), recently implemented a new decentralised on-call system in psychiatric emergencies. Videoconference (VC) studios are installed on the three regional psychiatric centres and in the homes of the psychiatrists that participate in the on-call system. The psychiatrists are accessible for the regional centres' ambulant psychiatric teams and acute psychiatric wards, and are able to take part in direct patient consultations by VC. In September 2011, the new on-call system was established in clinical practice for the regional psychiatric centres, and psychiatrists are now accessible by VC 24 hours a day, 7 days a week.

The purpose of the new VC on-call service is to ensure patients in the vicinity of the regional acute psychiatric wards, local access to specialist assessment. In accordance with current strategies of Northern Norway Regional Health Authority and the Ministry of Health and Care Services [30,31], the service also aims to reduce unnecessary, as well as compulsory, admissions in acute psychiatric wards, due to expectations of increased competence and collaboration between levels in health care services.

\section{Research questions}

This study aims to explore how tele-psychiatry can be a tool to improve decision-making and treatment of patients in psychiatric emergencies, by elaborating the following qualitative aspects of acute tele-psychiatry:

1) Which factors are of importance to facilitate or hinder use of videoconferencing in psychiatric emergencies?

2) How does videoconferencing matter in psychiatric emergencies for patients and patient involvement, and how are patients' perspectives ensured?

3) How does videoconferencing matter in psychiatric emergencies for professional practice and coordination between the various levels of mental health care provision?

4) How can use of videoconferencing stimulate the development of competence in rural psychiatric centres and primary psychiatric care over time?

\section{Theoretical concepts}

Although this study is empirically driven, certain theories and concepts will be useful in analysing the material. Normalization process theory [32] is especially tailored to study success and failures in implementation processes, in which telemedicine has served as original empirical input theory development. The concept of domestication of technology concerns the process through which artefacts are appropriated and reembedded in a local context when it is put to use [33]. Patient involvement and empowerment [34] are also relevant concepts in the analysis of patient experiences. These theoretical concepts are maintained and developed in the project as sensitising tools in the inductive analysis of empirical data. 


\section{Methods and analytical approach}

The research project is designed as an explorative case study [35] of the new VC service in operation. To explore patients' and health professionals' experiences, organisational changes and collaboration between the local and the specialist levels in mental health care delivery, a stepwise-deductive inductive (SDI) approach [36] and issue-focused analysis [37] will be applied. In this combination themes are developed inductively on basis of empirical data, and theoretical concepts are applied as sensitising concepts in later analytical stages. Because we are interested in the participants' experiences of VC consultations in psychiatric emergencies, in-depth interviews with users are preferred for generating data on participants' experiences of VC consultations in psychiatric emergencies. Patients, specialists, and local health personnel will be interviewed based on purposive sampling [38]. We estimate a need for 20 interviews, but the exact number of participants will be determined when $\mathrm{VC}$ is established thoroughly as a regular service. Recruitment of study participants was initiated in June 2012, and the interviews are expected to be completed in the mid of 2013.

The in-depth interviews focus on participants' experiences on using $\mathrm{VC}$ consultations in various situations, with support of a semi-structured interview-guide [39], applying a combination of structured questions and themes emerging in an inter-subjective dialogue [40]. All the informants will be interviewed face-to-face, and the interviews will be digitally recorded, transcribed and analysed. As part of the routine in Department South, the specialists and the local health emergency staff are asked to fill-in a standard log after every VC consultation to document important factors concerning the $\mathrm{VC}$ consultations; date and time, the initiator of the VC consultations, participants, issues consulted, results of the consultation and satisfaction. To complement the interviews, the material from these logs will be analysed as well.

The study protocol has been approved by the Regional Committee for Medical Research Ethics in Norway. Patients will be recruited based on voluntary participation, with written informed consent. The data material will be de-personalised and securely handled according to the ethical recommendations from the Regional Committee for Medical Research Ethics in Norway.

\section{Discussion}

This study explores whether and how the use of $\mathrm{VC}$ consultations can be a tool to improve decision-making and treatment of patients in acute psychiatric care. However, there are several barriers to adoption and regular use of telemedicine in emergency care, such as regulatory, financial and cultural [41]. Health care services are also shaped by traditional rules and routines, as well as division of labour [42]. The technology per se is not the only aspect for frequent use or non-use of telemedicine and e-health [24,42]. At our site of research, organisational changes have been implemented to facilitate the use of new technology. By exploring qualitative aspects of how VC consultations matter for patients and professional practice, the study will elaborate on clinical, cultural and organisational issues of implementation of telemedicine in psychiatric emergency care. Identifying factors that facilitate or hinder the use of videoconferencing in psychiatric emergencies, are expected to increase our knowledge on how VC consultations may be successfully implemented and organised in emergency psychiatry. Moreover, the study will analyse patients' experiences of $\mathrm{VC}$ as a communication medium in psychiatric emergencies, as well as implications for professional practice, organisational changes and collaboration between levels in psychiatric health care. In all, this knowledge can be used to develop new high-quality telemedicine services to improve health care for patients in rural areas, reduce needs for unnecessary transport of patients, and strengthen the collaboration and coordination between levels in health care delivery.

\section{Competing interests}

The authors declare that they have no competing interests.

\section{Authors' contributions}

MT contributed to the design of the study and drafted the manuscript. SRB, GØS and AT contributed to the design of the study and helped to draft the manuscript. All authors read and approved the final manuscript.

\section{Acknowledgements}

The study is supported by grants from Northern Norway Regional Health Authority through the Committee for Health Services, Coordination and Telemedicine Research Programme. We would like to thank Didrik Kilvær, Department South, General Psychiatric Clinic, University Hospital of North Norway, and Ann-Karin Furskognes, Norwegian Centre for Integrated Care and Telemedicine, University Hospital of North Norway, for valuable contributions.

\section{Author details}

${ }^{1}$ Norwegian Centre for Integrated Care and Telemedicine (NST), University Hospital of North Norway (UNN), P.O. Box 35, Tromsø N-9038, Norway. ${ }^{2}$ Division of Emergency Medical Services, University Hospital of North Norway (UNN), P.O. Box 45, Tromsø N-9038, Norway. ${ }^{3}$ Department South, General Psychiatric Clinic, University Hospital of North Norway (UNN), P.O. Box 6124, Tromsø N-9291, Norway. ${ }^{4}$ Department of Sociology and Political Science, Norwegian University of Science and Technology (NTNU),

Trondheim N-7491, Norway.

Received: 1 November 2012 Accepted: 18 December 2012 Published: 20 December 2012

\section{References}

1. WHO: Mental health: new understanding, new hope, The World Health Report. Geneva: World Health Organization; 2001.

2. Norwegian Institute of Public Health: Helsetilstanden i Norge Folkehelserapport 2010. (The Status of Public Health in Norway - Public Health Report 2010). Report. 2010: Oslo: Norwegian Institute of Public Health; 2010.

3. García-Lizana F, Muñoz-Mayorga: What about telepsychiatry? A systematic review. J Clin Psychiatry 2010, 12(2):1-5. 
4. Hetherington R, Baistow K: Supporting families with a mentally ill parent: European perspectives on interagency cooperation. Child Abuse Rev 2001, 10(5):351-365

5. Ministry of Health and Care Services: Statlig strategi 2004-2007. S@mspill 2007. Elektronisk samarbeid i helse- og sosialsektoren, (National Strategy for Norway 2004-2007. Te@mwork 2007 - Electronic cooperation in the Health and Social Sector). Oslo: Ministry of Health and Care Services; 2004.

6. Ministry of Health and Care Services: Samspill 2.0. Nasjonal strategi for elektronisk samhandling i helse- og omsorgssektoren 2008-2013 (Teamwork 2.0. National strategy for electronic interaction in the health and social sector 2008-2013). Oslo: Ministry of Health and Care Services; 2008

7. Ministry of Health and Care Services: St.meld. nr. 47: Samhandlingsreformen Rett behandling - på rett sted, til rett tid (Report No.47 to the Storting: The coordination reform. Proper treatment - at the right place and right time). Oslo: Ministry of Health and Care Services; 2009.

8. Boydell MK, Volpe T, Pignatiello A: A qualitative study of young people's perspectives on receiving psychiatric services via televideo. J Can Acad Child and Adolescent Psychiatr 2010, 19(1):5-11.

9. Pesämaa L, Ebeling $H$, Kuusimäki M-L, Winbland I, Isohanni M, Moilanen I: Videoconferencing in child and adolescent telepsychiatry: a systematic review of the literature. J Telemed Telecare 2004, 10(4):187-192.

10. Stensland GØ: Prosjektplan. Desentralisert vaktsamarbeid ved bruk av videokonferanse (Project Plan. Decentralised on-call system using videoconferencing). Tromsø: General Psychiatric Clinic, University Hospital of North Norway; 2009.

11. Greenberg N, Boydell MK, Volpe T: Pediatric telepsychiatry in Ontario: Caregiver and service provider perspectives. J Behav Health Serv Res 2006, 33(1):05-111.

12. Hilty DM, Luo JS, Morache C, Marcelo DA, Nesbitt TS: Telepsychiatry. An overview for psychiatrists. CNS Drugs 2002, 16(8):527-548.

13. Myers KM, Vander Stoep A, Mc Carty CA, Klein JB, Palmer NB, Geyer JR, Melzer SM: Child and adolescent telepsychiatry: variations in utilization, refferal pattens and practice trends. J Telemed Telecare 2010, 16:128-133.

14. De Las Cuevas C, Artiles J, De La Fuente J, Serrano P: Telepsychiatry in the Canary Islands: user acceptance and satisfaction. J Telemed Telecare 2003 9(4):221-224.

15. Bishop JE, O'Reilley RL, Maddox K, Hutchinson LJ: Client satisfaction in a feasibility study comparing face-to-face interviews with telepsychiatry. J Telemed Telecare 2002, 8(4):217-221.

16. Yellowlees P, Burke MM, Marks SL, Hilty DM, Shore JH: Emergency telepsychiatry. J Telemed Telecare 2008, 14(6):277-281.

17. Shore $\mathrm{JH}$, Hilty DM, Yellowlees P: Emergency management guidelines for telepsychiatry. Gen Hosp Psychiatry 2007, 29(3):199-206.

18. Sorvaniemi M, Ojanen E, Santamäki O: Telepsychiatry in emergency consultations: a follow-up study of sixty patients. Telemed J e-health 2005, 11(4):439-441.

19. Bolle SR, Larsen F, Hagen O, Gilbert M: Video conferencing versus telephone calls for team work across hospitals: a qualitative study on simulated emergencies. BMC Emerg Med 2009, 9:22.

20. Westbrook Jl, Coiera EW, Brear M, Stapleton S, Rob MI, Murphy M, Cregan P: Impact of an ultrabroadband emergency departement telemedicine system on the care of actuetly ill patients and clinicans' work. Medical J Aust 2008, 188(12):704-708.

21. Cregan P, Stapleton S, Wilson L, Qiao R-Y, Li J, Perceival T: The ViCCU Project - achieving virtual presence using Ultrabroadband internet in a Critical Clinical application - inital results. Stud Health Technol Inform 2005, 111:94-98.

22. Sandaunet A-G: A space for suffering? Communicating breast cancer in an online self-help context. Qual Health Res 2008, 18(12):1631-1641.

23. Broom A, Tovey P: The role of the Internet in cancer patients' engagement with complementary and alternative treatments. health: An Interdisiplinary J Soc Study of Health, IIIn Med 2008, 12(2):139-155.

24. Sandaunet A-G: The challenge of fitting in: non-participation and withdrawal from an online self-help group for breast cancer patients. Sociol Health IIIn 2008, 30(1):131-144.

25. Tjora A, Sandaunet A-G: Digitale pasienter (Digital patients). Oslo: Gyldendal Akademisk; 2010

26. Andreassen HK: What does an e-mail adress add? - Doing health and technology at home. Soc Sci Med 2011, 72(4):521-528.
27. Andreassen HK, Trondsen M: Pasient på e-post (Patient on e-mail). In Den moderne pasienten (The modern patient). Edited by Tjora A. Oslo: Gyldendal Akademisk; 2008.

28. May C, Gask L, Atkinson T, Ellis N, Mair F, Esmail A: Resisting and remoting new technologies in clinical practice: the case of telepsychiatry. Soc Sci Med 2001, 52(12):1889-1901.

29. Tjora A: Den tredimensjonale pasienten som velvillig teleradiologisk objekt (The three-dimensional patient as willing tele-radiological object). In Digitale pasienter (Digital patients). Edited by Tjora A, Sandaunet A-G. Oslo: Gyldendal Akademisk; 2010:247-265.

30. Northern Norway Regional Health Authority: Høringsuttkast - Redusert og riktig bruk av tvang i psykisk helsevern i Helse Nord. Tiltaksplan 2012-2015 (Draft Document - Reduced and correct use of restraints in mental health care in the Northern Norway Regional Health Authority. Action Program 2012-2015). Bodø: Northern Norway Regional Health Authority; 2011.

31. Ministry of Health and Care Services: St.meld. nr. 63 (1997-98): Om opptrappingsplan for psykisk helse 1996-2006. Endringer i statsbudsjettet for 1998 (Report No. 63 (1997-98) to the Storting: Escalation Plan for Mental Health 1996-2006. Changes in the state budget 1998). Oslo: Ministry of Health and Care Services; 1998.

32. May C, Finch T: Implementing, embedding and integration practices: an outline of normalization process theory. Sociology 2009, 43(3):535-554.

33. Lie M, Sørensen KH: Making technology our own? Domesticating technology into everyday life. Oslo: Scandinavian University Press; 1996.

34. Andreassen HK, Trondsen M: The empowered patient and the sociologist. Social Theory \& Health 2010, 8(3):280-287.

35. Yin RK: Case study research design and methods. Thousand Oaks: Sage; 2008.

36. Tjora A: Kvalitative forskningsmetoder i praksis (Qualitative research in practice). Oslo: Gyldendal Norsk Forlag; 2010.

37. Weiss RS: Learning from strangers. The art and method of qualitative interview studies. New York: Free Press; 1994.

38. Gobo G: Sampling, representativeness and generalizability. In Qualitative research practice. Edited by Seale C, Gobo G, Gubrium JF, Silverman D. London: Sage; 2007:405-426.

39. Kvale S: Interviews: an introduction to qualitative research interviewing Thousand Oaks, CA: Sage; 1996.

40. Rapley T: Interviews. In Qualitative research practice. Edited by Seale C, Gobo G, Gubrium JF, Silverman D. Los Angeles: Sage; 2007.

41. Rogove HJ, McArthur D, Demaerschalk BM, Vespa PM: Barriers to telemedicine: Survey of current users in acute care units. Telemed e-health 2011, 18(1):48-53.

42. Nilsen LL, Solvoll T: Traditional practice vs new tools and routines in stroke treatment. Future Internet 2012, 4(3):688-699.

doi:10.1186/1472-6963-12-470

Cite this article as: Trondsen et al:: VIDEOCARE: Decentralised psychiatric emergency care through videoconferencing. BMC Health Services Research 2012 12:470.

\section{Submit your next manuscript to BioMed Central and take full advantage of:}

- Convenient online submission

- Thorough peer review

- No space constraints or color figure charges

- Immediate publication on acceptance

- Inclusion in PubMed, CAS, Scopus and Google Scholar

- Research which is freely available for redistribution 